\title{
OCORRÊNCIA DE ACIDENTE DE TRABALHO POR MATERIAIS \\ PERFUROCORTANTES E FLUIDOS BIOLÓGICOS EM ESTUDANTES E \\ TRABALHADORES DA SAÚDE DE UM HOSPITAL ESCOLA DE BRASÍlIA1
}

\author{
OCCURRENCE OF WORK ACCIDENTS CAUSED BY SHARP-EDGED HOLLOW- \\ POINTED EQUIPMENT AND BIOLOGICAL FLUIDS AMONG MEDICAL STUDENTS \\ AND HEALTH PERSONNEL IN A BRASÍLIA UNIVERSITY HOSPITAL
}

\begin{abstract}
FRECUENCIA DE ACCIDENTES DEL TRABAJO CAUSADOS POR INSTRUMENTOS PUNTIAGUDO-CORTANTES Y FLUIDOS BIOLÓGICOS ENTRE ESTUDIANTES Y PERSONAL DE UN HOSPITAL ESCUELA DE LA CIUDAD DE BRASILIA
\end{abstract}

\author{
Helena Eri Shimizu* \\ Emílio José Gonçalves Ribeiro**
}

Shimizu HE, Ribeiro EJG. Ocorrência de acidente de trabalho por materiais perfurocortantes e fluidos biológicos em estudantes e trabalhadores da saúde de um hospital escola de Brasília. Rev Esc Enferm USP 2002; 36(4): $367-75$.

\begin{abstract}
RESUMO
estudo teve por objetivo verificar e analisar a ocorrência de acidentes de trabalho causados por materiais perfurocortantes e fluidos biológicos em estudantes e trabalhadores da área da saúde. Foi realizado em um hospital-escola de Brasilia. A coleta de dados foi feita a partir dos registros de acidentes de trabalho mantidos pela Comissão de Controle de Infecção Hospitalar e referentes ao periodo de agosto de 1998 a junho de 2000. Verificou-se que 117 pessoas sofreram acidentes de trabalho, em sua grande maioria causados por agulhas. Concluiu-se que existe a necessidade de melhoria nos sistemas de prevenção de acidentes na instituição.
\end{abstract}

PALAVRAS CHAVE: Acidentes de trabalho. Pessoal de saúde. Saúde ocupacional. Condições de trabalho.

\begin{abstract}
The objective of the study was to check and analyze the occurrence of work accidents caused by sharp-edged hollow-pointed equipment and biological fluids among medical students and health personnel. It was carried out in a Brasilia university hospital. The data were collected from records of work accidents kept by the Hospital Infection Control Committee, from August 1998 to June 2000. It has turned out that 117 persons were victims of work accidents, the vast majority of them caused by needles. The study has reached the conclusion that the accident prevention system must be improved at the above mentioned hospital.
\end{abstract}

KEYWORDS: Accidents, occupational. Health personnel. Occupational health. Working conditions.

\section{RESUMEN}

El objetivo del estudio fue el de verificar y analizar la frecuencia de accidentes del trabajo causados por instrumentos puntiagudo-cortantes entre estudiantes y personal de un hospital escuela de la ciudad de Brasilia. Los datos, recogidos de los registros de accidentes del trabajo de la Comisión de Control de Infección Hospitalaria, corresponden al periodo entre agosto de 1998 y junio de 2000. Se verifico que 117 personas sufrieron accidentes del trabajo, en su gran mayoria causados por agujas. Se llegó a la conclusión de que es necesario mejorar el sistema de prevención de accidentes en dicha institución.

PALABRAS-ClAVE: Accidentes de trabajo. Personal de salud. Salud ocupacional. Condiciones de trabajo.

\footnotetext{
Trabalho apresentado no $52^{\circ}$ Congresso Brasileiro de Enfermagem; 2000 out 21-26; Recife.

* Enfermeira. Mestre e Doutora em Enfermagem. Professora adjunta do Departamento de Enfermagem da Universidade de Brasilia

** Enfermeira. Especialista em Saúde Pública. Chefe do Serviço de Quimioterapia do Hospital Universitário de Brasília.
} 


\section{INTRODUÇÃO}

Sabe-se que os trabalhadores da saúde, que atuam na área hospitalar, estão expostos a inúmeros acidentes de trabalho, principalmente àqueles causados por materiais perfurocortantes e fluidos biológicos. Nos últimos tempos têm aumentado a preocupação com acidentes causados por este tipo de material, devido ao risco de o trabalhador contrair a Sindrome da Imunodeficiência Adquirida (AIDS) e o virus da Hepatite B e C.

Estudos mostram que ocorrem de uma a quatro soroconversões positivas por HIV (Virus da Imunodeficiência Humana) a cada 1.000 punções acidentais. A contaminação de trabalhadores da saúde por virus da Hepatite B é, porém, bastante alta, devido à sua alta capacidade infectante (risco médio de infecção de cerca de 3\%(1)). Por virus da Hepatite C é um pouco mais baixa, estando em cerca de 1,8\% (2).

O Center for Disease Control (CDC) criou, em 1988, um conjunto de recomendações destinadas aos profissionais de saúde, com o propósito de diminuir o risco de contaminação por HIV e Hepatite B Virus (HBV) no caso de contato com sangue e fluídos corporais $^{(3)}$. No Brasil, essas recomendações foram inicialmente traduzidas como precauções universais e, atualmente, são denominadas de precauções-padrão. $\mathrm{O}$ uso de tais medidas pressupõe que todos os profissionais podem ser potencialmente infectados com patógenos. Conseqüentemente, esses devem se prevenir com medidas de barreira, sempre que houver possibilidade de contato com sangue ou fluidos corporais. Faz-se necessário, porém, destacar que as precauções-padrão podem ajudar a reduzir, mas não eliminam o risco de exposição ocupacional.

Além disso, alguns estudos mostram que a adesão de estudantes e trabalhadores da saúde às medidas de precauções-padrão em hospitais é baixa(4_6). O estudo realizado por Lopes; Moromizato; Veiga (5) mostra que, mesmo após diversos treinamentos sobre o uso das precauções-padrão, os estudantes e trabalhadores da saúde não adotavam a lavagem das mãos antes e após a realização de procedimentos, bem como continuavam reencapando as agulhas utilizadas. Por este motivo, a instituição estudada teve que realizar campanhas sobre a importância da lavagem das mãos e da prevenção de acidentes com materiais perfurocortantes.

Santos $^{(7)}$ afirma que as doenças profissionais no Brasil ocorrem em índices superiores aos de qualquer epidemia que o país já vivenciou, demonstrando a precariedade das condições de trabalho.

Silveira, Robazzi, Luis( ${ }^{(8)}$ chamam a atenção, ainda, para o fato de que a não-notificação dos acidentes de trabalho é uma prática usual entre os trabalhadores brasileiros. Alguns estudos mostram que, grande número de trabalhadores da saúde não notifica o acidente de trabalho, por meio da Comunicação de Acidente de Trabalho (CAT), tanto devido ao desconhecimento da necessidade desse tipo de registro, quanto ao excesso de procedimentos burocráticos, entre outros motivos $(9,19)$. Outros estudos mostram que a subnotificação dos acidentes causados por materiais perfurocortantes e fluidos biológicos é bastante alta porque os profissionais da equipe de saúde dão pouca importância para esse tipo de acidente, apesar do constante risco de adquirir doenças $(4,11)$ Dentre os motivos apresentados por esses profissionais, destacam-se: a percepção de que a lesão é pequena e a crença de que não irá causar danos para

a sua saúde( $(4,11,12)$.

Os estudos que analisam a ocorrência dos acidentes de trabalho causados por materiais perfurocortantes e fluidos biológicos são de suma importância, porque podem trazer contribuições que auxiliem na redução desse tipo de acidentes nas instituições de saúde.

\section{Assim, o Objetivo geral deste estudo é:}

- Analisar a ocorrência de acidentes de trabalho causados por materiais perfurocortantes e fluidos biológicos em estudantes e trabalhadores da área da saúde em um hospital público e de ensino de Brasília.

Os objetivos específicos são identificar:

- Estudantes e trabalhadores mais expostos a acidentes de trabalho por materiais perfurocortantes e fluidos biológicos;

- Serviços onde ocorre maior número de acidentes por materiais perfurocortantes e fluidos biológicos;

- Tipos de materiais causadores de acidentes;

- Condutas tomadas pela instituição após os acidentes causados por materiais perfurocortantes e fluidos biológicos com os estudantes e trabalhadores da saúde.

\section{METODOLOGIA}

Trata-se de um estudo do tipo descritivo e exploratório. Foi realizado em um hospital-escola de Brasília, de nível terciário e de grande porte, que possui as seguintes unidades: Clinica Médica, Clínica Cirúrgica, Clínica Pediátrica, Pediatria Cirúrgica, Maternidade, Berçário, Centro Obstétrico, Centro Cirúrgico, Centro de Tratamento Intensivo Centro de Hemodiálise, Centro de Pronto Atendimento, Serviço de Quimioterapia e Ambulatório.

A coleta de dados foi feita a partir dos registros de acidentes de trabalho mantidos pela Comissão de Controle de Infecção Hospitalar (CCIH), visto fazer 
parte da rotina da instituição, a comunicação de todo e qualquer acidente de trabalho a esta Comissão. A amostra do estudo compreendeu a totalidade dos trabalhadores e estudantes da área da saúde que comunicaram a ocorrência de acidente por materiais perfurocortantes a $\mathrm{CCIH}$, no periodo de agosto de 1998 e junho de 2000.

\section{RESULTADOS E DISCUSSÃO}

Verificou-se que 117 pessoas notificaram os acidentes de trabalho com materiais perfurocortantes e fluidos biológicos a $\mathrm{CCIH}$, no período de maio de 1998 a junho de 2000.

Figura 01 = Distribuição de trabalhadores e estudantes da área da saúde que sofreram acidente de trabalho com materiais perfurocortantes e fluidos biológicos, no período de maio de 1998 a junho de 2000, num hospital escola do Distrito Federal.

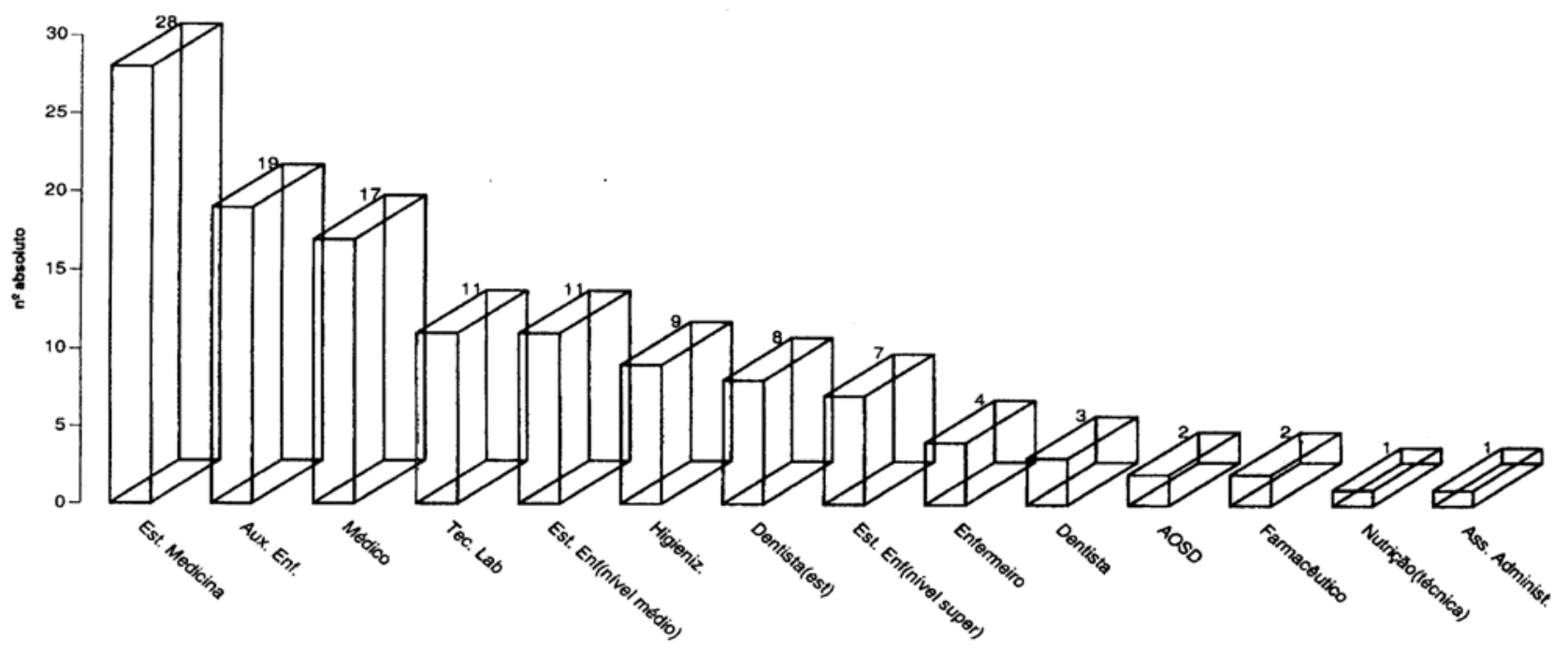

Conforme mostra a figura 1 , o maior número de acidentes de trabalho ocorreu entre os estudantes de medicina, talvez pelo fato de assumirem grande parte das coletas de exames de sangue de urgência dos pacientes internados. Outro fator que possivelmente explique o alto número de acidentes seria a falta de treinamento desses profissionais durante o curso de graduação, o que geraria falta da habilidade para realização desse tipo de procedimento.

Verifica-se na figura 1 que, depois dos estudantes de medicina, são os auxiliares de enfermagem os que mais sofrem acidentes de trabalho. Esses trabalhadores assumem a assistência direta aos pacientes e realizam procedimentos que os expõem ao risco de acidentes, como, por exemplo: preparo e administração de medicação, coleta de sangue, punção venosa e realização de glicemia capilar. O número de auxiliares de enfermagem também é proporcionalmente bastante reduzido, o que aumenta a chance de acidentes de trabalho, devido à necessidade de realizarem tarefas com rapidez.

A gravidade do quadro clínico dos pacientes, a complexidade dos cuidados e a carência de materiais e equipamentos adequados são também fatores que têm contribuído para aumentar o número de acidentes de trabalho entre os auxiliares de enfermagem.
Os médicos também estão expostos a acidentes com materiais perfurocortantes e fluidos biológicos, conforme ilustra a figura 1. Esses profissionais realizam, freqüentemente, a coleta de sangue para exames de urgência e procedimentos de maior complexidade, ou seja, àqueles que não são delegáveis aos alunos do curso de medicina, como, por exemplo: dissecção venosa, passagem de catéteres venosos e arteriais, passagem de dreno de tórax. Há que se destacar que nas unidades de internação são realizados alguns procedimentos de maior complexidade quando os pacientes correm risco de vida, o que aumenta a chance dos médicos se acidentarem.

Observa-se também na figura 1 que o número de técnicos de laboratório que sofreram acidentes de trabalho é bastante significativo, certamente pelo tipo de atividade que desenvolvem no laboratório e nas unidades de internação. Por haver falta de pessoal nas unidades de internação, eles geralmente realizam a coleta de sangue em pacientes com precárias condições venosas e/ou agitados, sem auxílio de outra pessoa. Já nos laboratórios, eles desenvolvem diversas atividades que os expõem a acidentes com materiais perfurocortantes.

Os estudantes de nível médio, cuja grande maioria realiza o curso de auxiliar de enfermagem, estão expostos a acidentes de trabalho na mesma proporção dos técnicos de laboratório (figura 1). É importante destacar que, na 
instituição estudada, os estudantes das escolas de nivel médio assumem a assistência no mesmo ritmo de profissionais já formados, devido à não reposição de auxiliares de enfermagem nos últimos anos. Assim sendo, esses alunos que, em geral, possuem poucas habilidades técnicas, precisam dar conta dos cuidados aos pacientes internados junto com os auxiliares de enfermagem da instituição.

Silva(13) constatou, em um estudo realizado com os trabalhadores de enfermagem de um hospital de ensino, que os atendentes de enfermagem foram os que mais se acidentaram $(60,7 \%)$, seguidos pelos auxiliares de enfermagem $(30,4 \%)$, e pelos enfermeiros $(8,9 \%)$. A autora acredita que o grau de qualificação profissional tem influenciado na ocorrência de acidentes de trabalho. Para ela, quanto menor o grau de qualificação profissional, maior o risco de sofrer acidente de trabalho.

Conforme demonstrado na figura 1 , o pessoal do serviço de higienização tem sofrido acidentes de trabalho, na maioria das vezes, por descuido dos demais trabalhadores da saúde, que descartam materiais perfurocortantes nas lixeiras das unidades. Nesse sentido é necessário ressaltar que é grande o número de estudantes que não recebem orientação nos cursos sobre a necessidade de descartar esse tipo de material em recipientes próprios. Outro fator que aumenta o risco de exposição desses trabalhadores a acidentes é a necessidade de coletar recipientes com excesso de materiais perfurocortantes.

Os estudantes de odontologia e enfermagem também sofrem acidentes de trabalho com materiais perfurocortantes (figura 1). Possivelmente, a falta de habilidade e a insegurança na realização de procedimentos são fatores que contribuem para ocorrência deste tipo de acidente.
Finalmente, constatamos que, embora em menor proporção, os enfermeiros, os dentistas, os auxiliares de serviços operacionais diversos (AOSD), os farmacêuticos, os técnicos de nutrição e os assistentes administrativos, estiveram expostos a acidentes de trabalho por materiais perfurocortantes (figura 1).

Em suma, os dados acima mostram que os estudantes e os trabalhadores da saúde que executam cuidados diretos aos pacientes, principalmente aqueles que utilizam objetos perfurantes ou cortantes na execução de procedimentos estão mais expostos a acidentes de trabalho com materiais perfurocortantes e fluidos biológicos.

Verifica-se a necessidade de realização de treinamentos sistematizados e contínuos sobre a prevenção desses acidentes, para estudantes e trabalhadores, a serem ministrados tanto nos cursos de formação como na instituição estudada.

E necessário ressaltar, porém, que os problemas relacionados ao ensino dessa temática ocorrem nos cursos de formação e nos serviços de educação continuada das instituições de saúde. Jansen ${ }^{(14)}$ verificou que o ensino sobre essa temática nos cursos de nível médio e graduação ocorre de forma não sistematizada e descontínua, o que resulta na não aplicação desses conhecimentos quando os alunos se inserem no campo de prática profissional. Outros estudos mostram que os trabalhadores das instituições de saúde recebem algumas orientações sobre prevenção de acidentes com materiais perfuro-cortantes e fluidos biológicos, porém têm dificuldades para colocá-los em prática(4-6,11). Esses resultados apontam a necessidade de uma discussão mais aprofundada entre as instituições formadoras e as de saúde, para. que encontrem estratégias de ensino mais eficientes para o desenvolvimento dessa temática a fim de minimizar o número de acidentes com esses materiais.

Figura 02 = Distribuição do acidente com materiais perfurocortantes e fluidos biológicos, segundo a Unidade onde ocorreu o acidente, no período de maio de 1998 a junho de 2000, em um hospital escola do Distrito Federal.

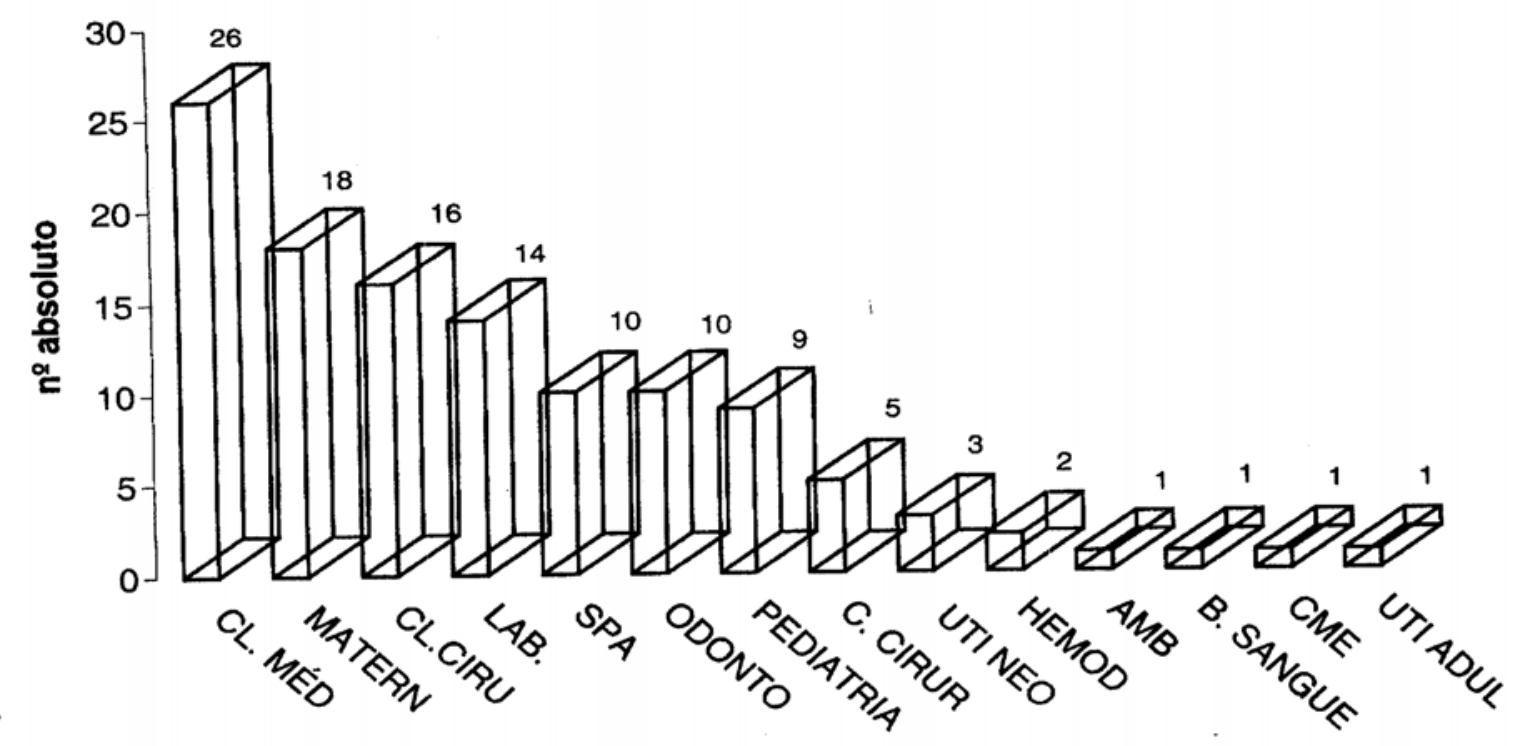


Conforme mostra a figura 2, identificou-se que o maior número de acidentes de trabalho por materiais perfurocortantes e fluidos biológicos, em ordem decrescente, ocorreu nas unidades de Clínica Médica, Maternidade/Centro Obstétrico e Clínica Cirúrgica, certamente devido à complexidade dos cuidados dos pacientes ali internados e ao ritmo intenso de trabalho e, principalmente, devido à falta de pessoal.

Constatou-se que, a seguir, destacam-se os seguintes serviços: Centro de Pronto Atendimento, Odontologia, Pediatria e Centro Cirúrgico, como pode ser visualizado na figura 2. Fica evidente que as características peculiares desses serviços, bem como as atividades desenvolvidas nessas unidades, expõem os

trabalhadores a acidentes de trabalho com materiais perfurocortantes e fluídos biológicos.

Verificou-se também a ocorrência de acidentes, em menor proporção, nas unidades especializadas e fechadas (UTI neonatal, Hemodiálise, Centro de Material e Esterilização, UTI adulto), como demonstra a figura 2. Pode-se inferir que, por serem unidades especializadas e fechadas, apesar da complexidade dos cuidados nessas unidades, os profissionais possuem maior destreza manual e também têm a possibilidade de desenvolver as atividades de forma mais planejada. Sarquis( ${ }^{(6)}$ atribui a menor freqüência de acidentes com materiais perfurocortantes em algumas unidades a dinâmica da unidade estabelecida pela formas de organização.

Por fim, verificou-se pequeno número de acidentes em unidades onde se realizam procedimentos de menor complexidade, como o ambulatório (figura 2).

Em suma, constatou-se que os acidentes causados por materiais perfurocortantes e fluidos biológicos ocorrem em praticamente todas as unidades do hospital, demonstrando a necessidade de implementação de programas de prevenção desses acidentes para todas as unidades, e voltados para cada área específica.

Figura 03 - Distribuição do acidente com materiais perfurocortantes e fluidos biológicos, segundo o objeto causador e material biológico causador, no período de maio de 1998 a junho de 2000.

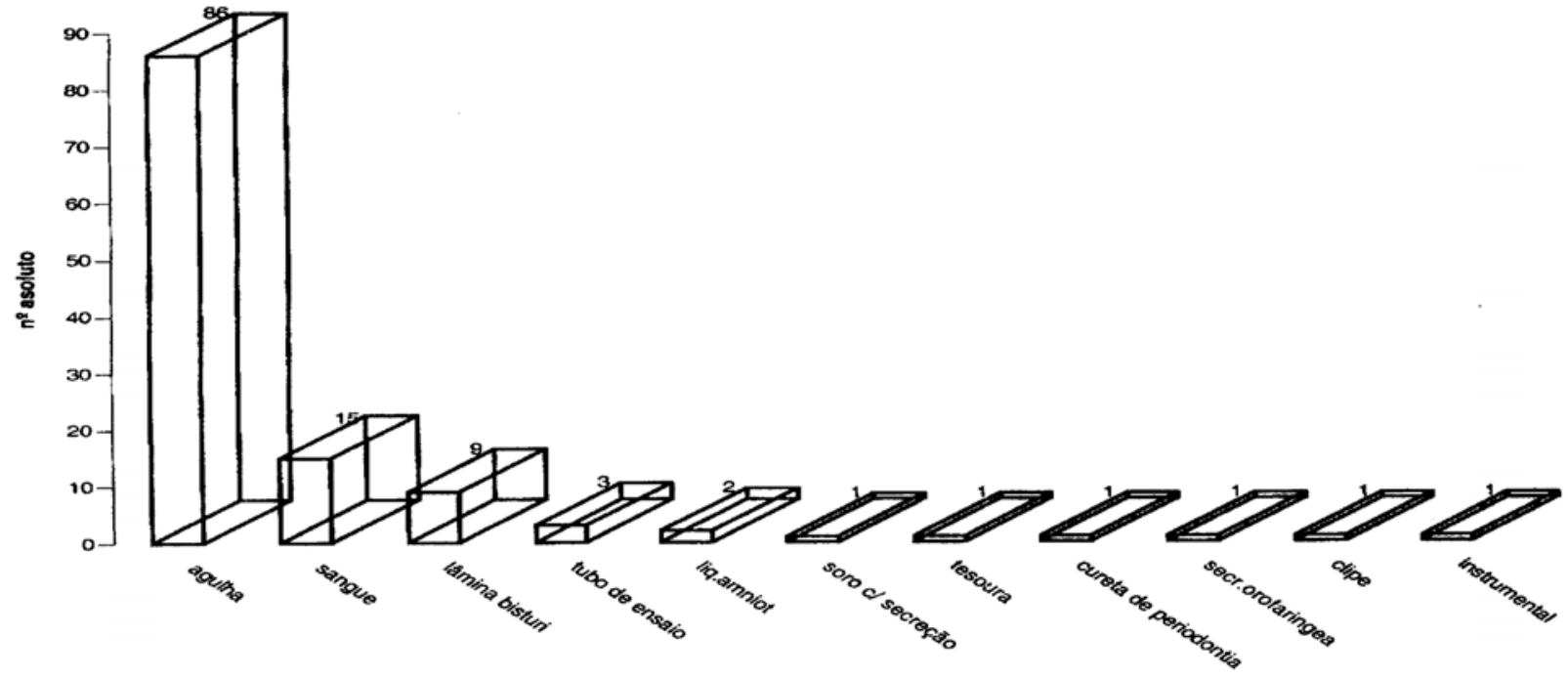

Constatou-se que a maioria dos acidentes é causada por agulhas, conforme ilustrado na figura 3. Diversos estudos mostram que o número de acidentes provocados por agulhas é bastante significativo ${ }^{4,6,6,9}$, $11,12,15,16,17)$ Esses acidentes ocorrem, em geral, devido à prática de reencape de agulhas antes do descarte, transporte de medicação a ser realizada sem bandeja, luvas de procedimentos maiores que o tamanho das mãos, falta de habilidade, agitação psicomotora do pacientes, entre outros.
É necessário ressaltar, contudo, que o estudo feito por Brevidelli(4) comprova que grande parte dos acidentes com agulhas ocorrem devido à prática de reencape da agulha. A pesquisadora examinou as caixas de materiais perfurocortantes e constatou que $53,4 \%$ das agulhas reencapadas e 46,6\% não estavam. Vale ressaltar que esse tipo de erro é cometido por trabalhadores que já receberam treinamento sobre o risco de terem acidente perfurante ao reencaparem agulhas ${ }^{(4-6)}$. Como estratégia para estimular o descarte 
de agulhas imediatamente após o seu uso existe a recomendação para colocar recipientes para descarte de materiais perfurocortantes próximo dos leitos ${ }^{(4)}$.

A falta ou do uso do tamanho incorreto das luvas, além de ferir as medidas contidas nas precauções-padrão, contribui para o aumento do número de acidentes causados por agulhas. Em estudo realizado em cinco hospitais(11), ao analisar o uso de luvas no momento do acidente com agulha, mostrou que, em apenas dois deles, este era superior a $80 \%$, sendo inferior a $50 \%$ nos demais. Além disso, verificou-se a utilização de tamanho de luvas incorreto por diversos trabalhadores ${ }^{(11)}$.

A Sociedade Brasileira de Infectologia(18) e o $\mathrm{CDC}^{(3)}$ têm se mostrado bastante preocupados com os acidentes causados por agulhas, sobretudo no que se refere à notificação dos acidentes e monitorização dos infectados, bem como à adoção de medidas de precauções-padrão pelos trabalhadores da saúde, visando à prevenção tanto da transmissão do vírus HIV quanto das Hepatites B e C.

Atualmente existem medidas profiláticas para $\mathrm{O}$ trabalhador que se acidenta com materiais contendo vírus HIV e a possibilidade de tomar a vacina contra a Hepatite B. Entretanto, ainda não existe vacina para a Hepatite C. Segundo o Ministério da Saúde, o risco médio de infecção pelo HCV é de $1,8 \%$, podendo variar de 1 a $10 \%(2)$. Canini (12) afirma que existe um risco estimado de 4\% após acidentes com matérias perfurocortantes que envolvem paciente fonte HCV positivo. Outro estudo mostra que esse risco pode variar entre 3 a $10 \%$, sendo que $30 \%$ dos infectados pelo HCV evoluem para a doença crônica (19). Esses dados demonstram que a prevenção da Hepatite C causada por materiais perfurocortantes deve ser visto como um grande desafio para as instituições de saúde,conseqüentemente para os profissionais envolvidos com essa problemática.
Detectou-se também que os estudantes e trabalhadores sofreram acidentes com sangue, conforme pode ser verificado na figura 3. Esse tipo de acidente geralmente ocorre por falta de uso do Equipamento de Proteção Individual (EPI), principalmente óculos, em procedimentos que os expõe ao contato com o sangue. Com relação à problemática do uso do EPI, alguns estudos mostram que a maioria dos trabalhadores da saúde conhece a importância do seu uso, porém não tem o cuidado de usá-lo ao prestar assistência aos pacientes $(4,5,11,14)$

O terceiro objeto causador de acidente de trabalho foi à lâmina de bisturi (figura 3). Faz-se necessário destacar que os trabalhadores de algumas áreas, como o centro cirúrgico e a central de material e esterilização, estão mais expostos a sofrerem acidentes com este tipo de material. Brandi; Benatti; Alexandre (9) detectaram, porém, que o uso inadequado da lâmina de bisturi para abrir frascos de soro tem sido fator causador de acidentes. Neste mesmo estudo constataram que $30,8 \%$ dos acidentados necessitaram que a ferida fosse suturada. Por fim, cabe ressaltar que os estudantes e trabalhadores precisariam ser reorientados quanto ao uso adequado da lâmina de bisturi bem como da sua retirada, logo após o seu uso, para evitar acidentes com outros trabalhadores que poderão manipulá-los.

Conforme pode ser visualizado na figura 3 , os outros objetos causadores de acidentes foram os tubos de ensaios, as tesouras, as curetas, os clipes e os instrumentais.

Por fim, dos materiais biológicos causadores dos acidentes detectaram-se: o líquido ammniótico, o soro contaminado com fluidos biológicos e a secreção de orofaringe (figura 3).

Figura 4 - Percentual de imunização contra a Hepatite B entre trabalhadores e estudantes da área da saúde que sofreram acidentes de trabalho com materiais perfurocortantes e biológicos (maio de 1998 a junho de 2000) em um hospital escola do DF.

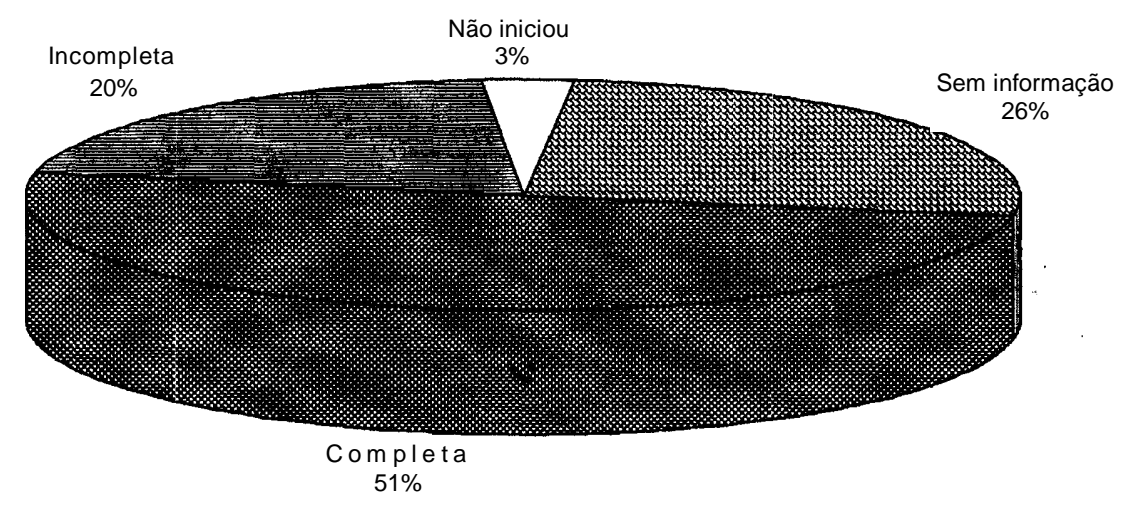


Verifica-se na figura 4 que número significativo de estudantes e trabalhadores da saúde imunizou-se contra Hepatite B. Grande parte desses, porém, não receberam o esquema completo $(20 \%)$. Constata-se, ainda, que $3 \%$ não tomaram nenhuma dose da vacina.

Os dados acima evidenciam também que os trabalhadores da saúde ainda desconhecem e/ou subestimam a possibilidade de adquirirem a Hepatite B por meio de acidentes que possam ocorrer ao cuidar dos pacientes. Outro estudo mostra que o número de trabalhadores da saúde que tomam a vacina da Hepatite B é baixo, mesmo após a ocorrência de acidentes com materiais perfurocortantes e/ou fluídos biológicos(9)

Nesse sentido é necessário ressaltar que, no cotidiano de trabalho nos hospitais os trabalhadores costumam demonstrar maior preocupação com a possibilidade de contaminação com o HIV Tal preocupação fica evidente quando se constata que os trabalhadores da saúde usam, ainda nos dias de hoje, mais de um par de luvas para manipular os pacientes soropositivos.

No Brasil, a preocupação com a imunização dos trabalhadores da saúde contra a Hepatite B surgiu tardiamente. Apesar da existência de estudos, na década de 80 , que mostrassem a contaminação de trabalhadores da saúde por acidentes de trabalho, o acesso à vacina era dificil, por ser importada. Dessa forma, apenas os trabalhadores que tinham maior poder aquisitivo tomavam a vacina contra a Hepatite $\mathrm{B}$, geralmente em clínicas particulares.
Na década de 90, alguns hospitais públicos começaram a oferecer as vacinas para os trabalhadores das áreas consideradas mais críticas, ou seja, onde os trabalhadores corriam maiores riscos de acidentes de trabalho e, consequentemente, contaminação com o virus da Hepatite B (como nas Unidades de Terapia Intensiva, Centro Cirúrgico, Serviço de Hemodiálise e Pronto Socorro). Posteriormente o acesso à vacina foi estendido aos demais trabalhadores da área da saúde, na maioria das instituições públicas de saúde.

$\mathrm{Na}$ instituição estudada houve, no início da década de 90, um movimento dos trabalhadores das áreas mais críticas (Unidade de Terapia Intensiva, Centro Cirúrgico, Serviço de Hemodiálise e Centro de Pronto Atendimento) para que se comprassem vacinas contra a Hepatite B.

Em suma, os dados acima demonstram que, atualmente, a instituição precisa ser mais eficiente na orientação dos estudantes e trabalhadores sobre a importância da vacinação para a Hepatite B. Além disso, a $\mathrm{CCIH}$ precisa melhorar os registros dos estudantes e trabalhadores a que sofreram acidentes de trabalho com materiais perfurocortantes e fluidos biológicos com indicação para receber a vacina da Hepatite B a fim de controlar a administração correta da vacina. Para tanto, sugere-se que a $\mathrm{CCIH}$ estabeleça uma comunicação mais eficiente com setor de imunização.

Figura 5 - Percentual de quimioprofilaxia para HIV em estudantes e trabalhadores da área da saúde que sofreram acidentes de trabalho com materiais perfurocortantes e biológicos (maio de 1998 a junho de 2000) em um hospital escola do DF.

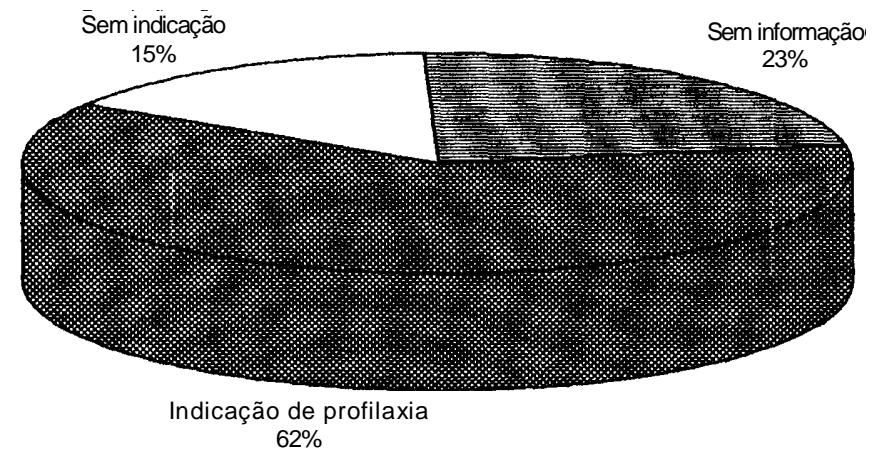

$\mathrm{O}$ risco de se adquirir HIV por exposição percutânea é bastante baixo, cerca de $0,3 \%$. Alguns fatores aumentam esse risco: ferimento profundo e/ ou sangue visivel no material causador do ferimento, ferimento com material previamente colocado em veia ou artéria do paciente, presença de alta carga viral, acidente envolvendo grande volume de sangue, maior tempo de exposição a secreções; presença da pele ou mucosa expostas e área extensa exposta(20)

A profilaxia com drogas anti-retrovirais pode reduzir a possibilidade de infecção por HIV Há estudo mostrando que o uso profilático de da Zidovudina (AZT) resultou em redução de $79 \%$ do risco de soroconversão após o acidente(20). 
A rotina da instituição preconiza o emprego do antiretroviral nas primeiras duas horas e, no máximo, vinte $\mathrm{e}$ quatro horas após o acidente, com tratamento de duração de quatro semanas. Entretanto, segundo informações da $\mathrm{CCIH}$ da instituição estudada, observa-se que muitos trabalhadores e estudantes abandonam o tratamento, devido à intolerância ao medicamento. Outro estudo (21) mostra que os trabalhadores da saúde costumam abandonar o tratamento com drogas antiretrovirais devido aos diversos efeitos colaterais. Além disso, constatou que muitos deles interrompem o uso da medicação porque acreditam que pode aumentar a chance de estarem realmente contaminados com o virus HIV Por fim, os resultados do estudo mostram que muitos trabalhadores têm medo de adquirir AIDS, principalmente pelo estigma da doença. Dessa forma, a profilaxia para a doença após acidente de trabalho precisa ser abordada com cuidado, ou seja, esclarecendo-se sobre a importância, os beneficios e efeitos colaterais.

Verifica-se também que a instituição precisa melhorar os registros dos estudantes e trabalhadores com indicação de quimioprofilaxia para HIV, para poder acompanhar se estão realizando o tratamento corretamente.

\section{CONSIDERAÇÕES FINAIS}

Os estudantes e trabalhadores da saúde têm, hoje, maior preocupação em registrar por materiais perfurocortantes e fluidos biológicos, visto terem sido notificados 117 acidentes no período de maio de 1998 a junho de 2000 na $\mathrm{CCIH}$ da instituição estudada. Possivelmente, o medo dos estudantes e trabalhadores da saúde de adquirirem a AIDS, Hepatite $\mathrm{B}$ e $\mathrm{C}$ tem contribuído para o aumento do registro do acidente na $\mathrm{CCIH}$.

Verificou-se que os estudantes e trabalhadores da saúde que realizam cuidados diretos aos pacientes e utilizam materiais perfurantes ou cortantes na execução de procedimentos estão mais expostos a acidentes de trabalho. Identificou-se ainda que esses acidentes ocorrem em praticamente todas as unidades do hospital, sendo mais freqüentes, como também demonstram outros estudos $(6,9)$, nas unidades onde o ritmo de trabalho é mais intenso, conseqüentemente $o$ desgaste do trabalhador é maior.

Com relação ao objeto causador do acidente perfurante ou cortante, identificaram-se: agulhas, lâminas de bisturi, tubos de ensaio, instrumentais, tesouras, curetas e os clipes. As agulhas, seguidas das lâminas, foram as responsáveis pelo maior número de acidentes. Dos fluidos biológicos identificaram-se: sangue, líquido amniótico, soro com secreção e secreção de orofaringe. Outros estudos apresentam resultados semelhantes, o que demonstra que estudantes e trabalhadores da saúde incorporaram alguns hábitos no cotidiano de trabalho que resulta na exposição freqüente aos acidentes com materiais perfurocortantes e fluidos biológicos. Alguns estudos mostram que os treinamentos que tratam da prevenção desse tipo de acidente não provocam mudanças no comportamento dos estudantes e trabalhadores da saúde que contribuam de modo significativo para a redução desses acidentes $(4,6)$. Certamente os estudantes e trabalhadores apresentam dificuldades para incorporar as medidas preventivas contidas nas precauções-padrão, porque requer nova aprendizagem e, principalmente, mudanças de hábitos.

Esses dados mostram que as instituições formadoras de profissionais da saúde e as de saúde precisam repensar as estratégias de ensino dessa temática, caso contrário os estudantes e trabalhadores continuarão expostos ao risco de adquirirem doenças causados por materiais perfurocortantes e fluidos biológicos.

É preciso acrescentar nessas instituições a possibilidade de participação mais ativa (estudantes e trabalhadores) no processo ensino-aprendizado da prevenção de acidentes com materiais perfurocortantes e fluidos biológicos, buscando instrumentalizá-los com saberes que, aplicados em sua prática diária, lhes assegurem, efetivamente, prevenção, proteção e segurança,

Além disso, é necessário investir em treinamentos continuos e sistematizados para os estudantes e trabalhadores da saúde que enfatizem os métodos de prevenção e os meios para proteção contra as doenças causadas por acidentes com materiais perfurocortantes e fluidos biológicos. Quanto a este último aspecto, verificou-se que a instituição precisa encontrar estratégias mais eficientes para tratar da importância da vacina da Hepatite $B$ e da quimioprofilaxia para HIV, para quando houver indicação, melhorar a adesão dos estudantes e trabalhadores ao tratamento.

Por fim, sugere-se uma melhor articulação entre Comissão de Controle de Infecção Hospitalar, Comissão Interna de Prevenção de Acidentes (CIPA), Serviço de Medicina do Trabalho (SESMT) e outros órgãos que se preocupam com os acidentes de trabalho, para que discutam as formas/medidas de prevenção de acidentes causados por materiais perfurocortantes e fluidos biológicos a fim de reduzir a exposição de estudantes e trabalhadores a esses acidentes. 


\section{REFERÊNCIAS BIBLIOGRÁFICAS}

(1) Jarne AR. Bioseguridad hospitatalaria: nuevo enfoque teórico. Acta Bioq Clin Latinoam 1990; 24:241-6.

(2) Ministério da Saúde. Secretaria de Politicas de Saúde. Coordenação Nacional de DST e AIDS. Manual de condutas: exposição ocupacional a material biológico: hepatite e HIV. Brasília; 1999.

(3) Center for Disease Control. Recommendations for prevention of HIV transmission in health-care settings. MMWR 1988; 36:3-17.

(4) Brevidelli MM. Exposição ocupacional ao vírus da AIDS e da hepatite B: análise da influência das crenças em saúde sobre a prática de reencapar agulhas.[dissertação] São Paulo (SP): Escola de Enfermagem da USP; 1997.

(5) Lopes MHBM, Moromizato SS, Veiga J FS. Adesão às medidas de precaução-padrão: relato de experiência. Rev LatAm Enferm 1999; 7: 83-88.

(6) Sarquis LMM. Acidentes de trabalho com instrumentos perfurocortantes: ocorrência entre trabalhadores de enfermagem. [dissertação] São Paulo (SP): Escola de Enfermagem da USP, 1999.

(7) Santos UP. Sistema de vigilância epidemiológica para acidentes de trabalho: uma experiência na Zona Norte do município de São Paulo (Brasil). Rev Saúde Pública 1990; 24: 286-93.

(8) Silveira EAA, Robazzi MLC, Luis MAAV. Varredores de rua: acidentes de trabalho ocorridos na cidade de Ribeirão Preto, Estado de São Paulo-Brasil. Rev Lat-Am Enferm 1998; 6: 71-79.

(9) Brandi S, Benatti, MCC, Alexandre NMC. Ocorrência de acidente de trabalho por material perfurocortante entre trabalhadores de enfermagem de um Hospital Universitário da Cidade de Campinas do Estado de São Paulo. Rev Esc Enferm USP 1998; 32:124-33.

(10) Napoleão AM. Causas de subnotificação de acidentes de trabalho: visão dos trabalhadores de enfermagem de um hospital do interior paulista. [dissertação] Ribeirão Preto (SP): Escola de Enfermagem de Ribeirão Preto/USP, 1999.

(11) Souza M. Acidentes ocupacionais e situações de risco para a equipe de enfermagem. [doutorado] São Paulo (SP): Escola Paulista de Medicina da Universidade Federal de São Paulo, 1999.

(12) Canini, SEM. Situação de risco para transmissão de patógenos veiculados pelo sangue entre a equipe de enfermagem de um hospital universitário do interior paulista. [dissertação] Ribeirão Preto (SP): Escola de Enfermagem de Ribeirão Preto/USP, 2000.

(13) Silva VE. Estudo sobre acidentes de trabalho ocorridos com os trabalhadores de enfermagem de um hospital de ensino. [dissertação] São Paulo (SP): Escola de Enfermagem da USP; 1988.

(14)
Jansen AC. Um novo olhar para acidentes de trabalho: a questão do ensino. [dissertação] Ribeirão Preto (SP): Escola de Enfermagem de Ribeirão Preto/USP, 1997.

(15) Benatti MCC. Acidentes de trabalho entre trabalhadores de enfermagem de um hospital universitário. Rev Esc Enferm USP 2001;35:155-62.

(16) Yassi MGM. Determinants of blood and body fluid exposure in a large teaching hospital: hazards of the intermittent intravenous procedure. Am J Infect Control 1991;19: 129-35.

(17) Gir E, Costa FPP, Silva AMA. Enfermagem frente a acidentes de trabalho com material potencialmente contaminado na era do HIV Rev Esc Enferm USP 1998; 32: $262-72$

(18) Sociedade Brasileira de Infectologia. Informativo. 1995; 3:1.

(19) Gerberding JL. Does Knowledge of human immunodeficiency virus infection decrease the frequency of occupational exposure to blood? Am J Med 1991; 91: 308-11.

(20) Secretaria da Saúde. Recomendações para quimioprofilaxia da exposição ocupacional material potencialmente contaminado com HIV. Brasília; 1997.

(21) Azambuja EP. O processo de trabalho e o processo educativo: construindo a prevenção da situação de risco e acidente de trabalho.[dissertação] Santa Catarina (SC): Universidade Federal; 1999. 